3. Akbarpour Samaneh, Khalili Davood, Zeraati Hojjat, Mansournia Mohammad Ali, Ramezankhani Azra \& Fotouhi Akbar.(2018). Healthy lifestyle behaviors and control of hypertension among adult hypertensive patients. Scientific Reports,8(8508):1-9.

4. Lim SS, Vos T, Flaxman AD, et al. (2012). A comparative risk assessment of burden of disease and injury attributable to 67 risk factors and risk factor clusters in 21 regions, 1990-2010: a systematic analysis for the Global Burden of Disease Study. 2010. Lancet. 380:2224-2260.

5. Moura André, Almeida Godoy, Simone de Cesarino, Cláudia Bernard (2016). Factors determining non-adherence to hypertension treatment. Fundamental Nursing Master by
University of Sao Paulo. Brazil,34-35.

6. Morisky DE, DiMatteo MR (2011). Improving the measurement of self-reported medication nonadherence: Final response. J Clin Epidem. 64:258-263.

7. Niklas Arkadiusz, Flotyńska Anna, PuchWalczak Aleksandra, Polakowska Maria, et al.(2018). Prevalence, awareness, treatment and control of hypertension in the adult Polish population - Multi-center National Population Health Examination Surveys - WOBASZ studies. Arch Med Sci.,14(5): 951-961

8. Park Kyong, Cho Sukyung, Bower Julie K. (2016). Changes in Adherence to NonPharmacological Guidelines for Hypertension. PLOS ONE. 11(8): e0161712

\title{
NGHIÊN CỨU SỰ THAY ĐỔI NỒNG Độ MộT SỐ CYTOKIN Ở BÊ̂NH VẨY NẾN THÔNG THƯỜNG MỨC Độ NĂNG TRƯớC VÀ SAU ĐIỀU TRI BẰNG CYCLOSPORIN A
}

\section{TÓM TẮT}

Mục tiêu: Xác định sự thay đổi nồng độ các cytokin IL-2, IL-6, IL-8, IL-10, IL-12, IL-17, INF- $\gamma$, TNF-a của bệnh nhân vảy nến thông thường mức độ nặng trước và sau điều trị bằng Cyclosporin $A$. Đối tượng và phương pháp: 35 bệnh nhân vảy nến thông thường mức độ nặng điêuu trị ngoai trú tai phòng khám chuyên đề bênh vảy nến-bênh viên Da liễu trung ương từ 10/2016-10/2019 được định lượng nông độ các cytokine IL-2, IL-6, IL-8, IL-10, IL-12, IL-17, INF- $\gamma$, TNF- $a$ trong huyết thanh trước và sau điêu trị bằng Cyclosporin A. Kết quả: Nồng độ các cytokine IL-2, IL6, IL-8, IL-10, IL-12, IL-17, TNF- a trước và sau điều trị thay đổi không có ý nghĩa thống kê, với $p>0,05$, tuy nhiên nồng độ INF- $\gamma$ huyết thanh sau điều trị đã giảm có ý nghĩa thống kê, với $p<0,05$. Kết luân: Sau 10 tuần điêuu trị bệnh vảy nến thông thường mức độ nặng bằng uống Cyclosporin $A$ liêu $2,5-3 \mathrm{mg} / \mathrm{kg} / \mathrm{ngày}$ thì nồng độ một số cytokine IL-2, IL-6, IL-8, IL-10, IL-12, IL-17, TNF- a huyết thanh chưa thay đổi. Tuy nhiên nồng độ INF- $\gamma$ sau điều trị giảm rõ rệt.

Tư khóa: Bệnh vảy nến thông thường mức độ nặng, interleukin $2,6,8,10,12,17$, INF- $\gamma$, TNF- a.

\section{SUMMARY \\ EVALUATED THE CONCENTRATION OF CYTOKINES IN SEVERE PSORIASIS VULGARIS WAS TREATED BY CYCLOSPORINE A}

\footnotetext{
*Bệnh viện Quân y 103,

**Bênh viện TUQQĐ 108

Chiu trách nhiêm chính: Lê Thị Hồng Thanh

Email: bsthanhdl103@gmail.com

Ngày nhận bài:20/1/2021

Ngày phản biên khoa học: 22/2/2021

Ngày duyệt bài: 5/3/2021
}

\section{Lê Thị Hồng Thanh*, Đặng Văn Em**}

Objective: To evaluated the concentration of cytokines: IL-2, IL-6, IL-8, IL-10, IL-12, IL-17, INF- $\boldsymbol{Y}$, TNF-a in patients with severe psoriasis vulgaris was treated by Cyclosporine A. Subject and method: 35 out-patients with severe psoriasis vulgaris had treated at National Dermatology Hospital from October2016 to October 2019were quantified concentration of cytokines IL-2, IL-6, IL -8, IL-10, IL-12, IL-17, INF- $\boldsymbol{Y}$, TNF-a in serum before and after treatment with Cyclosporine A (daily dose $2,5-3 \mathrm{mg} / \mathrm{kg} /$ day) in 10 weeks. Result: The concentration of cytokines IL-2, IL-6, IL-8, IL-10, IL-12, IL-17, TNF-a before and after treatment was not changed that has statistically significant with $p>0.05$. However, the concentration of INF-r $r$ after treatment reduced that significantly, with $p<0.05$. Conclusion: Patients with severe psoriasis vulgaris were treated by Cyclosporine A (daily dose $2,5-3 \mathrm{mg} / \mathrm{kg} /$ day) have not changed the concentrations of IL-2, IL-6, IL-8, IL-10, IL-12, IL-17, TNF-a after 10 weeks. However, the concentration of INF- $\boldsymbol{Y}$ has reduced that statisticallysignificantly.

Keywords: Severe psoriaisis vulgaris, IL-2, IL-4, IL-6, IL-8, IL-10, IL-17, INF- $\gamma$, TNF-a.

\section{I. ĐĂT VẤN ĐỀ}

Bệnh vảy nến là một bệnh da mạn tính, hay gặp. Bệnh chiếm 1,5 - 5\% dân số thế giới [1], [2]. Đến nay, đa số các nhà nghiên cứu đã thống nhất bệnh vảy nến là bệnh da di truyền, bệnh da do gen, có cơ chế miễn dịch, có hiện tượng tăng sinh quá mức tế bào thượng bì và được khởi động bởi một số yếu tố (stress, nhiễm khuẩn, chấn thương cở học, vật lý, thời tiết, vai trò của thuốc, thức ăn...). Có nhiều cytokine tham gia vào cơ chế bệnh sinh bệnh vảy nến nhưng trục IL-23/TH17 đóng vai trò trung tâm 
[1],[3]. Cytokine là những protein có trọng lượng phân tử thấp do các tế bào miễn dịch tiết ra. Đáp ứng qua trung gian cytokine là một quá trình phức tạp, khi sản xuất quá mức các cytokine trong da và huyết thanh đã dẫn đến tăng sinh, biệt hoá các tế bào keratin cũng như các tế bào miễn dịch gây nên tổn thương bệnh vảy nến [4]. Trong huyết thanh bệnh nhân vảy nến có tăng một số cytokine như IL-2, IL-6, IL-8, IL-10, IL-12, IL-17, TNF-a... đặc biệt trong các trường hợp vảy nến mức độ nặng [4]. Cho đến nay, điều trị bệnh vảy nến đã có nhiều triển vọng với một số thuốc sinh học mới nhưng Cyclosporin A vẫn là phương pháp có hiệu quả nhanh, đáp ứng tốt [1].

Xác định sư thay đổi nồng độ một số cytokine trong máu bệnh nhân vảy nển thông thường mức độ nặng trước và sau điêu trị bằng uống Cyclosporin $A$ là nội dung cần thiết và đến nay tại Việt Nam chưa có nghiên cứu nào công bố.

\section{II. ĐỐI TƯỢNG VÀ PHƯƠNG PHÁP NGHIÊN CỨU}

2.1. Đối tượng. Đối tượng gồm 35 bệnh nhân chẩn đoán xác định vảy nến thông thường mức độ nặng, điều trị ngoại trú tại phòng khám chuyên đề bệnh vảy nến-Bệnh viện Da liễu trung ương từ 10/2016-10/2019.

Tiêu chuẩn chọn. Bệnh nhân vảy nến thông thường mức độ nặng, trên 18 tuổi, mọi giới, không có chống chỉ định dùng Cyclosporin $A$, bệnh nhân đồng ý tham gia nghiên cứu.

Tiêu chuẩn loại trừ. Các thể vảy nến khác, có chống chỉ định dùng Cyclosporin $A$, bệnh nhân không đồng ý tham gia nghiên cứu, đang sử dụng các thuốc đường toàn thân khác, đang mắc các bệnh nhiễm trùng cấp hoặc mạn tính.

\subsection{Phương pháp}

Thiết kế nghiên cứu: Phương pháp mô tả cắt ngang, tiến cứu.

Các bước tiến hành: Khám, tuyển chọn bệnh nhân vảy nến thông thường mức độ nặng, lấy máu xét nghiệm, để tủ lanh âm $80^{\circ} \mathrm{C}$ và định lượng cytokin được tiến hành tại Labo miễn dịch của Bộ môn Miễn dịch, Học viện Quân y. Bệnh nhân được làm các xét nghiệm cần thiết, điều trị bằng uống Cyclosprin $A$ liêu $2,5-3 \mathrm{mg} / \mathrm{kg} / \mathrm{ngày}$.

Định lượng IL-2, IL-6, IL-8, IL-10, IL-12,IL17 , INF- $\gamma$, TNF-a trong huyết thanh trước và sau khi điều trị 10 tuần. Máu được ly tâm tách huyết thanh bảo quản tủ lạnh âm $80^{\circ} \mathrm{C}$ cho đến khi xét nghiệm.

Định lượng cytokine được tiến hành tại labo miễn dịch của Bộ môn Miễn dịch, Học viện Quân y. 20.0 .

2.3. Xử lý số liệu: Bằng chương trình SPSS

\section{KẾT QUẢ NGHIÊN CỨU}

3.1. Đặc điểm đối tượng nghiên cứu

Bảng 1. Đặc điểm đổi tượng nghiên cứu

\begin{tabular}{|c|c|}
\hline Chỉ số & Đặc điếm đối tượng \\
\hline Tuối & $53,97 \pm 13,980$ \\
\hline Giới: - Nam & $21(60 \%)$ \\
- Nữ & $14(40 \%)$ \\
\hline Mức độ bệnh: Nặng & $35(100 \%)$ \\
\hline
\end{tabular}

Nhận xét: Tuổi trung bình 53,97, trong đó nam chiếm đa số $60 \%$.

\subsection{Kết quả nồng độ một số cytokine huyết thanh trước và sau điêu trị}

Bảng 2. Nồng độ một số cytokine trước-sau điều trị $(n=35)$

\begin{tabular}{|c|c|c|c|}
\hline Cytokine & Trước điêu trị & Sau điều trị & p \\
\hline $\mathrm{IL}-2(\mathrm{pg} / \mathrm{ml})$ & $2,000 \pm 0,000$ & $2,000 \pm 0,000$ & $>0,05$ \\
\hline $\mathrm{IL}-6(\mathrm{pg} / \mathrm{ml})$ & $42,266 \pm 98,348$ & $16,218 \pm 40,005$ & $>0,05$ \\
\hline $\mathrm{IL}-8(\mathrm{pg} / \mathrm{ml})$ & $495,150 \pm 783,798$ & $609,801 \pm 902,116$ & $>0,05$ \\
\hline $\mathrm{IL}-10(\mathrm{pg} / \mathrm{ml})$ & $3,919 \pm 3,835$ & $3,403 \pm 2,995$ & $>0,05$ \\
\hline $\mathrm{IL}-12(\mathrm{pg} / \mathrm{ml})$ & $1,471 \pm 0,689$ & $1,461 \pm 0,603$ & $>0,05$ \\
\hline $\mathrm{IL}-17(\mathrm{pg} / \mathrm{ml})$ & $1,037 \pm 2,107$ & $0,654 \pm 0,835$ & $>0,05$ \\
\hline $\mathrm{TNF}-\mathrm{a}(\mathrm{pg} / \mathrm{ml})$ & $4,884 \pm 7,777$ & $3,548 \pm 1,394$ & $>0,05$ \\
\hline $\mathrm{INF}-\gamma(\mathrm{pg} / \mathrm{ml})$ & $2,366 \pm 3,236$ & $1,430 \pm 0,525$ & $<0,05$ \\
\hline
\end{tabular}

Nhận xét: Trước và sau điều trị nồng độ một số cytokine thay đối không có ý nghĩa thống kê với $\mathrm{p}>0,05$. Tuy nhiên nồng độ IFN- $\gamma$ giảm sau điêu trị có ý nghĩa thống kê với $\mathrm{p}<0,05$.

3.3. Liên quan giữa nồng độ một số cytokine với kết quả điêu trị

Bảng 3. Liên quan giữa nồng độ một số cytokine trước điều trị với kết quả điều trị

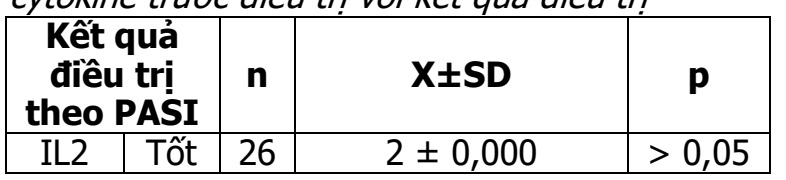

\begin{tabular}{|c|c|c|c|c|}
\hline & Khá & 8 & $2 \pm 0,000$ & \\
\hline \multirow{2}{*}{ IL6 } & Tốt & 26 & $51,171 \pm 112,064$ & \multirow{2}{*}{$>0,05$} \\
\cline { 2 - 4 } & Khá & 8 & $17,763 \pm 31,117$ & \\
\hline \multirow{2}{*}{ IL8 } & Tốt & 26 & $597,622 \pm 880,685$ & \multirow{2}{*}{$>0,05$} \\
\cline { 2 - 4 } & Khá & 8 & $220,691 \pm 239,705$ & \\
\hline \multirow{2}{*}{ IL10 } & Tốt & 26 & $3,856 \pm 4,103$ & $>0,05$ \\
\cline { 2 - 4 } & Khá & 8 & $3,088 \pm 0,844$ & $>0,05$ \\
\hline IL12 & Tốt & 26 & $1,545 \pm 0,740$ & $>0,05$ \\
\hline
\end{tabular}




\begin{tabular}{|c|c|c|c|c|}
\hline & Khá & 8 & $1,239 \pm 0,515$ & \\
\hline \multirow{2}{*}{ IL17 } & Tốt & 26 & $1,147 \pm 2,423$ & \multirow{2}{*}{$>0,05$} \\
\cline { 2 - 4 } & Khá & 8 & $0,758 \pm 0,633$ & \\
\hline \multirow{2}{*}{$\begin{array}{c}\text { TNF- } \\
\text { a }\end{array}$} & Tốt & 26 & $5,113 \pm 8,818$ & \multirow{2}{*}{0,05} \\
\cline { 2 - 4 } & Khá & 8 & $4,498 \pm 3,812$ & \\
\hline $\begin{array}{c}\text { IFN- } \\
\text { Y }\end{array}$ & Tốt & 26 & $1,961 \pm 1,463$ & \multirow{2}{*}{$>0,05$} \\
\cline { 2 - 4 } & Khá & 8 & $3,794 \pm 6,338$ & \\
\hline
\end{tabular}

Nhânn xét: Không có mối liên quan giữa nồng độ một số cytokine trước điều trị với kết quả điêu trị ở nhóm nghiên cứu với $p>0,05$.

Bảng 4. Liên quan giữa nồng độ một sô cytokine sau điều trị với kêt quả điều trị

\begin{tabular}{|c|c|c|c|c|}
\hline \multicolumn{2}{|c|}{$\begin{array}{c}\text { Kết quả } \\
\text { đîêu trì } \\
\text { theo PASI }\end{array}$} & \multirow{2}{*}{$\begin{array}{l}\mathbf{n} \\
26 \\
\end{array}$} & \multirow{2}{*}{$\begin{array}{c}\text { X士SD } \\
2 \pm 0,000 \\
\end{array}$} & \multirow{3}{*}{$\begin{array}{c}\mathbf{p} \\
>0,05\end{array}$} \\
\hline \multirow{2}{*}{ IL2 } & Tốt & & & \\
\hline & Khá & 8 & $2 \pm 0,000$ & \\
\hline \multirow{2}{*}{ IL6 } & Tốt & 26 & $15,170 \pm 41,514$ & \multirow{2}{*}{$>0,05$} \\
\hline & Khá & 8 & $20,805 \pm 39,719$ & \\
\hline \multirow{2}{*}{ IL8 } & Tốt & 26 & $651,544 \pm 1015,960$ & \multirow{2}{*}{$>0,05$} \\
\hline & Khá & 8 & $416,073 \pm 431,610$ & \\
\hline \multirow{2}{*}{ IL10 } & Tốt & 26 & $2,861 \pm 1,076$ & \multirow{2}{*}{$>0,05$} \\
\hline & Khá & 8 & $3,162 \pm 1,242$ & \\
\hline \multirow{2}{*}{ IL12 } & Tốt & 26 & $1,476 \pm 0,683$ & \multirow{2}{*}{$>0,05$} \\
\hline & Khá & 8 & $1,423 \pm 0,315$ & \\
\hline \multirow{2}{*}{ IL17 } & Tốt & 26 & $0,555 \pm 0,507$ & \multirow{2}{*}{$>0,05$} \\
\hline & Khá & 8 & $0,468 \pm 0,147$ & \\
\hline \multirow{2}{*}{$\begin{array}{l}\text { TNF } \\
-a\end{array}$} & Tốt & 26 & $3,533 \pm 1,483$ & \multirow{2}{*}{$>0,05$} \\
\hline & Khá & 8 & $3,515 \pm 1,235$ & \\
\hline \multirow{2}{*}{$\begin{array}{c}\text { IFN- } \\
\mathrm{Y}\end{array}$} & Tốt & 26 & $1,437 \pm 0,576$ & \multirow{2}{*}{$>0,05$} \\
\hline & Khá & 8 & $1,374 \pm 0,371$ & \\
\hline
\end{tabular}

Nhân xét: Không có mối liên quan giữa nồng độ một số cytokine sau điều trị với kết quả điêu trị ở nhóm nghiên cứu với p>0,05.

\section{BÀN LUÂ̂N}

4.1. Đăc điểm đối tượng nghiên cứu. Kết quả nghiên cứu của chúng tôi tại bảng 1 cho thấy, tuổi trung bình của nhóm nghiên cứu là $53,97 \pm 13,98$, nam chiếm $60 \%$, nữ $40 \%$.

4.2. Kết quả định lượng nồng độ một số cytokine huyết thanh trước và sau điêu tri. Kết quả của chúng tôi tại bảng 2 cho thấy nông đô IL-6, IL-10, IL-12, IL-17, TNF- ๔ sau điều trị đểu giảm hơn so với trước điều trị, tuy nhiên sự thay đổi chưa có ý nghĩa thống kê với p>0,05. Nông độ IL-2, IL-8 không có sự thay đổi so với trước điêu trị với $p>0,05$. Riêng nồng độ IFN- $y$ sau điêu trị giảm so với trước điều trị có ý nghĩa thống kê với $p<0,05$. Điều này cho thấy trong bệnh vảy nến mặc dù triệu chứng lâm sàng có cải thiện nhưng các thay đổi miễn dịch chưa rõ ràng, đây là một yếu tố duy trì sự mạn tính của tổn thương vảy nến.
Ở Việt Nam hiện tại chúng tôi chưa tham khảo được nghiên cứu nào về thay đổi nồng độ các cytokine sau điêu trị bệnh vảy nến thông thường bằng cyclosporine $A$. Chỉ có một vài nghiên cứu về thay đổi nồng độ các cytokine ở bệnh nhân vảy nến thông thường bằng các thuốc khác. Như Phạm Diễm Thuý và cS (2019) cho thấy, nồng độ các cytokin IL-2, IL-4, IL-8, IL-10, IL-17, TNF- $\alpha$, IFN- $Y$ sau điêu trị bằng chiếu UVB-311nm kết hợp uống Methotrexate liêu thấp (7,5mg/tuân), sự thay đổi so với trước điều trị chưa có ý nghĩa thống kê với $p>0,05$. Riêng IL-6 sau điêu trị giảm rõ rệt với $p<0,001$ [5]. Phan Huy Thục (2015), nghiên cứu ở 52 bệnh nhân vảy nến thông thường mức độ vừa nặng sau điêu trị bằng Methotrexate với liêu 7,5mg/tuân, nồng độ IL-17, TNF- $\alpha$, IFN- $y$ thấp hơn so với trước điều trị với $p<0,05$. Không có sự khác biệt trước và sau điêu trị với các cytokin IL-2, IL-4, IL-8, IL-10, IL-23 với $p>0,05$ [6]. Nghiên cứu của chúng tôi và các tác giả đều cho thấy sau điều trị nồng độ các cytokine đều có sự thay đổi (sau điêu trị thấp hơn so với trước điêu trị) nhưng sự thay đổi này chưa đủ lớn để có sự khác biệt có ý nghĩa thống kê, chỉ một vài cytokine thay đổi có ý nghĩa thống kê. Cho thây bệnh vảy nến là một bệnh lý mạn tính, luôn có sự hiện diện của các yếu tố miễn dịch duy trì bềnh. Do đó điều tri khi đạt được hiệu quả trên lâm sàng vẫn cân liệu pháp để duy trì tình trạng bệnh ổn định tránh tái phát vượng bệnh.

Theo Haider. A và cs (2008), nghiên cứu ở 11 bệnh nhân vảy nến thông thườngđiêuu trị bằng Cyclosporin A liêu $4 \mathrm{mg} / \mathrm{kg} / \mathrm{ngày}$ trong 8 tuân nhận thấy nồng độ các cytokin IL-17, IL-22, TNF- $\alpha$, IFN- Y giảm sau điêu trị [7]. Tuy nhiên theo nghiên cứu của chúng tôi thì IL-17, TNF- $\propto$ thay đổi chưa có ý nghĩa thống kê. Sự khác biệt này có thể do cõ mẫu nghiên cứu của Haider. A nhỏ $(n=11)$.

Theo Ikonomidis. I và cs (2017), sau khi điêu trị 50 bệnh nhân vảy nến thông thường bằng Cyclosporin A liều 2,5 - 3mg/kg/ngày trong vòng 16 tuân cho thây, nồng độ IL-6, IL-17 giảm có ý nghĩa thống kê với $p<0,05$, trong khi IL-10, IL12, TNF-alpha thay đổi chưa có sự khác biệt với $p>0,05$ [8]. Nghiên cứu của chúng tôi có sự khác biệt với các tác giả, có thể do liều CyA điêu trị và thời gian điều trị ở các nghiên cứu là khác nhau, do đó kết quả định lượng nồng độ các cytokine có thể khác nhau.

4.3. Liên quan giữa nông độ một số cytokine với kết quả điêuu tri. Kết quả nghiên cứu của chúng tôi tại bảng 3; 4 cho thây: không 
có sự liên quan giữa nồng độ các cytokine trước và sau điều trị với kết quả điều trị.

Hiện nay các nghiên cứu ở trong và ngoài nước về mối liên quan giữa nồng độ các cytokine (IL-2, IL-6, IL-8, IL-10, IL-12, IL-17, TNF- $\alpha$, IFN- $Y$ ) trước và sau điêu trị với kết quả điều trị chưa được công bố. Do vậy, trong nghiên cứu này chúng tôi còn hạn chế đó là: chưa có tài liệu tham khảo để so sánh về nội dung này.

\section{KẾT LUẬN}

Nghiên cứu 35 bệnh nhân vảy nến thông thường mức độ nặng, điều trị bằng uống Cyclosporin A với liểu 2,5-3mg/kg/ngàysau 10 tuần, chúng tôi rút ra một số kết luận:

Nồng độ IL-6, IL-10, IL-12, IL-17, TNF-c sau điêu trị đều giảm hơn so với trước điêu trị, tuy nhiên sự thay đổi chưa có ý nghĩa thông kê với $p>0,05$. Nồng độ IL-2, IL-8 không có sự thay đổi so với trước điều trị với $p>0,05$. Riêng nồng độ IFN- y sau điêu trị giảm so với trước điều trị có ý nghĩa thống kê với $p<0,05$.

Chưa thấy mối liên quan giữa nồng độ một số cytokine trước và sau điêu trị với kết quả điều trị trên lâm sàng theo PASI.

\section{TÀI LIÊU THAM KHẢO}

1. Đặng Văn Em. (2013). Bệnh vảy nến: Sinh bệnh hộc và chiến lược điều trị. Sách chuyên khảo Nhà xuất bản y học., 236 tr.
2. WHO. (2016). The burden of psoriasis. Global report on psoriasis., Chapter 2.

3. Hawkes. J. E., Chan. T. C., Krueqer. J. G. (2017). Psoriasis pathoqenesis and the development of novel targeted immune therapies. Journal of Allergy and Clinical Immunoloqv., 140(3): 645-653.

4. Coimbra. S., Fiqueiredo. A., Castro. E., et al. (2012). The roles of cells and cytokines in the pathogenesis of psoriasis. International journal of dermatology., 51(4): 389-398.

5. Pham Diếm Thuý., Đăng Văn Em., Lý Tuấn Khải. (2019). Nghiên cứu sự thay đổi nồng độ môt số cytokine trước và cytokine trước và sau điều trị bệnh vảy nến thông thường bằng chiếu UVB-311nm kết hợp uống Methotrexate liều thấp. Tap chí y dược lâm sàng 108., 3.

6. Phan Huy Thuuc. (2015). Nghiên cứu đặc điểm lâm sàng và mối liên quan giữa nồng độ cytokine với kết quả điều trị bệnh vảy nến thông thường bằng methotrexate. Luận án tiến sỹ y học, Đại học Y hà nôi., 129 tr.

7. Haider. A. S., Lowes. M. A., Suárez-Fariñas. M., et al. (2008). Identification of cellular pathways of" type 1," Th17 T cells, and TNF-and inducible nitric oxide svnthase-producina dendritic cells in autoimmune inflammation through pharmacogenomic study of cyclosporine $A$ in psoriasis. Journal of immunoloqv., 180(3): 1913.

8. Ikonomidis. I., Papadavid. E., Makavos. G., et al. (2017). Lowering interleukin-12 activity improves myocardial and vascular function compared with tumor necrosis factor-a antagonism or cyclosporine in psoriasis. Circulation: Cardiovascular Imaging., 10(9): 006283.

\section{KHẢO SÁT MộT SỐ ĐĂC ĐIỂM VỀ HÌNH THÁI TỔN THƯƠ'NG TRONG HộI CHỬNG ĐộNG MẠCH CHỦ NGỰC CẤP}

\section{TÓM TẮT}

Mục tiêu: khảo sát tỷ lệ và mô tả một số đặc điểm về hình thái tổn thương trong hội chứng ĐMic ngực cấp ở nhóm bệnh nhân được nghiên cứu. Đối tượng và phương pháp nghiên cứu: Mô tả tiến cứu, hàng loạt các trường hợp. Bn được chẩn đoán một trong các thể của HC ĐMC ngực cấp và được điều trị tại khoa phẫu thuật tim, bệnh viện Chợ Râyy và khoa phẫu thuật tim mạch, bệnh viện Đaạ Học Y Dược trong thời gian từ tháng 9/2015 đến tháng 9/2018. Kết quả: Trong thời gian 3 năm (9/2015-9/2018), chúng tôi thu thập được 102 trường hợp được chẩn

\footnotetext{
${ }^{1}$ Bệnh viện Quân y 175

${ }^{2}$ Bềnh viện Đại hơ Y Dướ TPHCM

Chịu trách nhiệm chính: Nông Hữu Thọ

Email: huuthomd@gmail.com

Ngày nhận bài: 10/1/2021

Ngày phản biên khoa hoc: 9/2/2021

Ngày duyệt bài: 3/3/2021
}

\section{Nông Hữu Thộ ${ }^{1}$ Phạm Thọ Tuấn Anh ${ }^{2}$, Nguyễn Hoàng Định ${ }^{2}$}

đoán hội chứng ĐMC cấp. Sau khi được hội chẩn tim mạch, có 101 ca được điều trị phẫu thuật. Nhóm tuổi chiếm tỷ lệ cao nhất là độ tuổi $61-70$ tuổi (45,8\%). Các dạng hình thái tổn thương: Nhóm bóc tách kinh điển (AD) chiếm tỷ lệ cao nhất $66,3 \%$, nhóm phình dọa võ (AAR) là 23,8\%, nhóm loét thủng (PAU) là $8,9 \%$, nhóm huyết khối tu thành (IMH) là 23,8\%. Trong $\mathrm{HC}$ ĐMC cấp, vị trí tổn thương chủ yếulà ĐMC ngực đoan lên $(74,3 \%)$. Các vị trí khác có tỷ lệ tổn thương ít gặp hơn, tổn thương đoạn quai $(54,5 \%)$, tổn thương đoạn gốc ĐMC $(29,7 \%)$. Kết luận: Hình thái tổn thương trong hội chứng ĐMC ngực cấp khá đa dang và phức tap, thường gặp vẫn là dạng hình thái bóc tách ĐMC kinh điển $(A D)$ chiếm tỷ lệ cao nhất $66,3 \%$; các hình thái ít găp hơn là loét thủng PAU $8,9 \%$ và huyết khối tụ thành IMH 23,8\%. Tổn thương có thể gặp ở nhiều vị trí khác nhau và chồng lấn lên nhau, thường gặp nhất là ĐMC đoạn lên là 74,3\%. đoạn quai $54,4 \%$.

Từ khóa: Hội chứng động mạch chủ cấp, bóc tách, Huyết khối tụ thành, phình ĐMC. 